\title{
Um olhar sobre as Decisões Monocráticas e Colegiadas, Fundamentação e uso de Precedentes do CPC 2015 no âmbito das Câmaras Cíveis do Tribunal de Justiça do Rio de Janeiro
}

\author{
A look at Monocratic and Collegiate Decisions, Rationale and use \\ of Precedents of CPC 2015 within the scope of the Civil Chambers \\ of the Court of Justice of Rio de Janeiro
}

Adriano Moura da Fonseca Pinto ${ }^{1}$

\begin{abstract}
RESUMO
O presente trabalho retrata os resultados de atividade de pesquisa científica realizada no ano de 2017 tendo como objeto o conjunto de decisões monocráticas e acórdãos proferidos pelas Câmaras Cíveis e de Consumidores do Tribunal de Justiça do Estado do Rio de Janeiro. Foram analisadas a ocorrência de determinadas expressões jurídicas, incluindo citação a artigos de lei com o objetivo de identificar o perfil de fundamentação das decisões, bem como a adoção ou não de julgamentos com base em precedentes judiciais, conforme previsão do CPC 2015 e CRFB 88.
\end{abstract}

PALAVRAS-CHAVE:

Fundamentação, Precedente, Decisão, Acórdão.

\begin{abstract}
This paper presents the results of a scientific research activity carried out in the year 2017, having as its object the set of monocratic decisions and judgments handed down by the Civil and Consumer Chambers of the Court of Justice of the State of Rio de Janeiro. The occurrence of certain legal expressions was analyzed, including citation to articles of law with the objective of identifying the reasoning profile of the decisions, as well as the adoption or not of judgments based on judicial precedents, as predicted by CPC 2015 and CRFB 88 .
\end{abstract}

KEYWORDS:

Rationale, Precedents, Decision, Collegiate.

\footnotetext{
${ }^{1}$ Coordenador Adjunto e Professor Permanente do Programa de Pós-Graduação Stricto Sensu em Direito (PPGD) da Universidade Estácio de Sá. Professor dos Cursos de Graduação e Pós-Graduação em Direito da Universidade Estácio de Sá. Gestor nacional dos Cursos de Pós-Graduação Lato Sensu em Direito Yduqs/Estácio. Membro da Law and Society Association - LSA (Washington, DC - USA). Membros dos Observatórios de Política Pública, Direito e Proteção Social e Mediação. Membro da Comissão de Estudos em Processo Civil da OAB/RJ. Membro do Comitê Científico da Conferência Universitária para el Estudo de La Mediación y el Conflicto (CUEMYC). Consultor Internacional de la FACPYA - Universidad Autônoma de Nuevo Leon (Monterrey, México).
} 


\section{INTRODUÇÃO}

O acesso à Justiça nos Estados denominados como "Estado de Direito" é tema de extrema regulação e aclamação por parte da sociedade e seus respectivos representante no campo político, incluindo o Poder Judiciário, bem as demais funções essenciais ao funcionamento do respectivo aparato de responder pelo Direito e com o Direito. O tema tem passado por campos diversos, envolvendo teorias neoliberais ${ }^{2}$, como será visto mais a frente.

Pois bem, em meio ao campo de atuação de advogados privados e públicos, juízes, promotores e outros personagens de presença constante nos edifícios do art. 92 da CRFB de 1988, certamente os juízes, desembargadores e ministros têm um papel de destaque, uma vez que são eles que detém, ao menos no campo do discurso formal, a caneta do Direito.

E como fundamentam o uso da caneta, tais juízes, desembargadores e ministros? Em outras palavras e, à guisa do paralelo simplificado do art. 93, IX da CRFB de 1988, quais são as possibilidades de atender ao comando constitucional de que todas as decisões do Poder Judiciário devem ser também fundamentadas? A resposta parece ser simples e a pergunta então, desnecessária, mas a prática jurídica não permite que a conclusão seja assim, previsivelmente simples.

Em que pese as obras jurídicas de Introdução ao Estudo do Direito tradicionalmente comungarem das chamadas "fontes" do Direito como sendo aquelas que permitem ao Judiciário fundamentar suas decisões, o ordenamento jurídico pátrio, em especial destaque as normas constitucionais e infraconstitucionais destinadas ao Direito Processual têm sido objeto de constante e intenso câmbio, de modo a mesclar ao sistema processual brasileiro com institutos democratizantes, mais próximos aos existentes nos sistemas processuais de países da common $l a w{ }^{3}$ e que corriqueiramente são denominados de precedentes, decisões vinculantes, súmulas de observação ou vinculação mandatória, conforme previsão constitucional e infraconstitucional.

\footnotetext{
${ }^{2}$ MARINONI, Luiz Guilherme. Teoria Geral do Processo. Curso de Processo Civil. Vol 1. São Paulo: Editora Revista dos Tribunais, 2010, p. 43.

${ }^{3}$ CATHARINA, Alexandre de Castro. Movimentos Sociais e a construção dos procedentes judiciais. Curitiba: Ed. Juruá, 2015, p. 175.
} 
Tal câmbio, longe de estar exclusivamente vinculado ao surgimento da Lei 13.105 de 17 de 2015 que instituiu o novo Código de Processo Civil no Brasil, ganhou fôlego durante os anos de 1990 e 2000, até praticamente o advento da referida codificação, com as constantes reformas processuais que passou nossa legislação, período que ficou conhecido como sendo palco dos “Movimentos Reformadores”, com destaque para os períodos de 1994/1995, 1998/2002 e, posteriormente `a Emenda Constitucional 45/2004, ao último grande período de reformas, partindo de 2005 até a chegada do CPC 2015. ${ }^{4}$

Considerando a temática das formas de uso de precedentes e seu papel na construção de algumas decisões judicias no espaço do Tribunal de Justiça do Rio de Janeiro que se pretende abordar no presente trabalho, é importante reviver, ainda que no tempo e espaço da codificação pretérita, mas pós CRFB de 1988, modificações que foram permitindo o uso, cada vez mais direto ( e não se afirma ser aqui isso bom ou ruim) de decisões proferidas nos autos de processos jurídicos de outrem.

Um ponto de extremo interesse para a trilha inicial do presente trabalho é alteração realizada em 1998 pela Lei 9.756 de 17.12, que deu nova redação ao artigo 557 do CPC 1973, permitindo que o desembargador relator, proferisse monocraticamente, decisões pautadas na manifesta inadmissibilidade, improcedente, prejudicado ou, que muito nos interessa, “ ou em confronto com súmula ou jurisprudência dominante do respectivo tribunal, do Supremo Tribunal Federal ou de Tribunal Superior", conforme previsão do caput do referido artigo.

Além da previsão do caput, o parágrafo 1-A do finado artigo 557 do CPC 1973, em total desarmonia com ordem lógica e textual do caput, também, de modo implicitamente mandatório, mas que logo caiu no gosto explícito, também permitiu ao desembargado relator dar provimento ao recurso, nos casos em que o recurso estivesse alinhado com súmula ou com jurisprudência dominante do respectivo tribunal, do Supremo Tribunal Federal ou de Tribunal Superior.

Outros meios relevantes de iniciação ao campo de formação de jurisprudência dominante também existiam no CPC 1973, como incidente de Uniformização de Jurisprudência, previsto nos artigos 476-479, a prevenção ou composição de divergências

\footnotetext{
${ }^{4}$ PINTO, Adriano Moura da Fonseca; LUCAS, Isabella Pena; ALMEIDA, Marcelo Pereira de; NETO, Ubirajara da Fonseca. Na Marcha da Reforma Processual. Comentários às Leis 11.382/06; 11.417/06; 11.418/06; 11.419/06; 11.441/07; 11.448/07 e outras anotações. Rio de Janeiro: Freitas Bastos Editora, 2007, p. 51.
} 
jurisprudências do art. 555, com redação instituída em 2001, as importantes regulamentações e alterações reflexas da Emenda Constitucional 45/2004, como a repercussão geral no Recurso Extraordinário, os Recursos Especiais Repetitivos, a sentença de improcedência liminar do pedido, as súmulas impeditivas de recursos e também as súmulas vinculantes no âmbito do STF.

O mais desavisado processualista notou que após 2006, o exercício da ação, jurisdição e defesa no âmbito do processo judicial e administrativo seria algo um pouco mais do que "de razoável duração," 5 ainda que as causas ou consequências estivessem (ou ainda estejam) um pouco confusas e as muitas das vezes contraditórias. A ótica e ordem da Lei, Doutrina e Jurisprudência teria sofrido um grande baque, ainda que não definitivo. Já em curso tomava, cada vez mais fôlego, a caminhada até agora irreversível do conflito do direito individual de acesso à justiça (via jurisdição) em face das respostas judiciárias de repercussão vinculante, pautadas inicial e principalmente na solução de conflitos de massa, sem prejuízo das críticas doutrinárias a respeito da metodologia eleita. ${ }^{6}$

Ultrapassado o início da trilha, o caminho segue rumo ao CPC 2015, que chegou após longa e exaustiva operação de retalho da codificação anterior para fins de alinhamento com as previsões e interpretação constitucional. Nesse meio tempo que começa nos anos 1990 e chega a segunda década do século XXI, aparece (ou ganha mais visibilidade) a prática de maior (ainda) valorização da função dos princípios $^{7}$ em nosso ordenamento e sistema processual, mormente no campo Constitucional. Seja pela natural necessidade e posicionamento do Supremo nas décadas pós CRFB de $1988^{8}$, seja pelo reflexo no campo doutrinário e jurisprudencial dos tribunais locais e superiores, que a reboque do fenômeno da constitucionalização do Direito.

\footnotetext{
${ }^{5}$ Em referência ao art. 5 $5^{\circ}$ LXXVIII da CRFB de 1988.

${ }^{6}$ A respeito do tema: ALMEIDA, Marcelo Pereira de. Precedentes Judiciais. Análise Crítica dos Métodos Empregados no Brasil para a solução de Demandas de Massa. Curitiba: Juruá Editora, 2014.

${ }^{7}$ DA COSTA, José Augusto Galdino. Princípios Gerais no Processo Civil. Princípios Fundamentais e Princípios Informativos. Rio de Janeiro: Ed. Forense, 2007, p. 1-2. Ver também AVILA, H., Teoria dos Princípios da definição à aplicação dos Princípios jurídicos. São Paulo: Ed. Malheiros, 2014, p. 55.

${ }^{8}$ Para maior detalhamento a respeito da atuação do Supremo Tribunal Federal nas décadas pós CRFB 88: WENECK VIANNA, L. ... [et al]. A judiciaização da política e das relações sociais no Brasil. Rio de Janeiro: Ed. Revan, 1999.
} 
Não demora muito e o redimensionamento e leitura dos "Princípios Constitucionais" atinge outras denominações, como no caso do Neoconstitucionalismo ${ }^{9}$ ou Neoconsticionalismos ${ }^{10}$ e suas repercussões no ordenamento jurídico pátrioe é nesse ambiente que surge o CPC 2015, com a CRFB 88 em sua essência literal, com especial destaque aos $\operatorname{artigos} 1^{\circ}$ a 12 , que muito lembram a Emenda Constitucional 45/2004.

\section{AS IDEIAS DA INVESTIGAÇÃO REALIZADA E OS RESULTADOS ENCONTRADOS}

Sem prejuízo de outras tantas importantes modificações e, considerando o escopo do presente trabalho, será dado destaque do CPC 2015 aos institutos que modificam a fundamentação dos pronunciamentos judiciais, em especial sua maior normatização textual como espécie (ou tentativa formal de) interpretação do artigo 93, IX da Constituição da República Federativa do Brasil.

Em meio às novas possibilidades e restrições normativas do novo diploma processual, também interessa os chamados "precedentes legais", sem prejuízo das discussões e delongas doutrinárias que existem a respeito da expressão, suas origens e aplicação ${ }^{11}$, que certamente têm sua função no campo de se pensar e atuar o direito, mas que por opção e limitações metodológicas não se estenderão aqui no presente artigo.

Interessa enxergar números e dados contidos em julgamentos das Câmaras Cíveis do Tribunal de Justiça do Rio de Janeiro em prol de identificar características da atuação judiciária na vigência do CPC 2015, em especial quanto ao uso da fundamentação adequada prevista no

\footnotetext{
${ }^{9}$ MOLLER, M., Teoria Geral do Neconstitucionalismo, Bases Teóricas do Constitucionalismo Contemporâneo. Porto Alegre: Ed. Livraria do Advogado,2011, p.50.

${ }^{10}$ MARTÍN, Nuria Belloso. O neoconstitucionalismo e o "novo" constitucionalismo latinoamericano:

Duas correntes possíveis de entendimento? In, Revista Culturas Jurídicas. Teoria Crítica Teoria Crítica, Pluralismo Jurídico e as Américas, Pluralismo Jurídico e as Américas. Vol. 4, Núm. 9, set./dez., 2017, pp. 24-54. Ver também, RODRIGUES, Saulo Tarso. Teoria da Decisão Judicial e Teoria da Justiça. Jusfilosofia e Novos Paradigmas Constitucionais. [et al]. Curitiba: Juruá, 2015.

11 PEREIRA, Fabrício de Souza Lopes. Resolução de Demandas Repetitivas, Ações Coletivas e Precedentes Judiciais. Curitiba: Juruá, 2017, p.81.
} 
seu artigo 489, com especial destaque aos precedentes legais e a sua utilização por parte de desembargadores em decisões monocráticas e colegiadas nas Câmaras Cíveis.

O artigo 489, $1^{\circ}$, apresenta em seus incisos V e VI do CPC 2015, disposições pertinentes ao uso e não uso de precedentes como parte integrante da fundamentação das decisões judiciais, que se interpretados em conjunto com o artigo. 932, IV e VI, resultam na ferramenta que desembargadores relatores dispõem para proferir suas decisões monocráticas, relatórios e votos respectivos.

Se antes da vigência do diploma processual de 2015, os artigos 458 e seguintes do CPC 1973, associados às disposições da LICC (depois LINDB), bem como o artigo 93, IX da Constituição da República Federativa do Brasil delimitavam o campo normativo da fundamentação das decisões judiciais e acompanhamentos doutrinários de ponderação de interesses etc $^{12}$, a partir de março de 2018, os juízes, desembargadores e ministros passam a dispor de um marco mais objetivo a respeito do tema.

Sem prejuízo da existência do marco legal, inclusive quanto à consagração dos valores e normas fundamentais da CRFB 88 na ordem, disciplina e interpretação do novo diploma processual, é seguro afirmar que os julgadores aplicam tal marco em sua essência? É correto afirmar que a partir da vigência do novo dispositivo os tribunais (principalmente) se descolaram ou se adequaram ao novo paradigma em suas decisões?

O autor do presente trabalho atua no ensino, pesquisa e extensão no campo do Direito, bem como na militante advocacia e buscou na pela investigação inicialmente quantitativa, percorrer caminhos em busca de cenários da operação judiciária no âmbito das Câmaras Cíveis e de Consumo no âmbito do Tribunal de Justiça do Rio de Janeiro no âmbito das atividades forenses do ano de 2017.

Nesse contexto e, no âmbito do Programa Pesquisa Produtividade UNESA, em projeto intitulado "Os precedentes no CPC/2015: um retrato das decisões no âmbito do Tribunal de Justiça do Estado Rio de Janeiro.", a investigação buscou selecionar ementas das decisões monocráticas e colegiadas da $1^{\mathrm{a}}$ a $27^{\mathrm{a}}$ Câmara Cível do Tribunal de Justiça com respectivos

\footnotetext{
${ }^{12}$ RODRIGUES, Saulo Tarso. Teoria da Decisão Judicial e Teoria da Justiça. Jusfilosofia e Novos Paradigmas Constitucionais. [et al]. Curitiba: Juruá, 2015, pp;509.
} 
julgamentos ocorridos de janeiro a dezembro de 2017, através de consultas à jurisprudência do Poder Judiciário do Estado do Rio de Janeiro no sítio www.tjrj.jus.br, bem como outros meios de leitura ou recebimento das respectivas ementas.

A investigação também procurou mapear antes quais seriam as melhores opções para realização das atividades de seleção de julgados e optou, já em certo momento crucial do cronograma de planejamento, em buscar as decisões monocráticas e colegiadas das Câmaras Cíveis considerando o aspecto mais abrangente e quantitativo possível de de ementas e julgados de interesse, sem prejuízo da existência de institutos de repercussão plural, tal como o IRDR Incidente de Resolução de Demandas Repetitivas, bem a o IAC -Incidente de Assunção de Competência, mas que tem um número muito menos expressivo de julgados para a análise, sem falar da especificidade temática em si, o que poderia comprometer a análise mais.

Para a realização de busca, seleção e análise quantitativa e qualitativo das referidas decisões em face ao tema proposto no projeto de pesquisa referenciado, foram selecionados os termos que melhor refletiam a tipicidade normativa das hipóteses de fundamentação e uso de precedentes no âmbito da CRFB 1988 e do CPC 2015.

Assim, as expressões jurídicas inicialmente selecionadas e respectivos objetivos específicos de cada um seguem abaixo tabelados: ${ }^{13}$

TABELA 1 - EXPRESSÕES JURÍDICAS E OBJETIVOS INICIAIS

\begin{tabular}{|c|c|}
\hline Expressões Jurídicas & Objetivos iniciais \\
\hline Fundamentação e Precedente & $\begin{array}{l}\text { Identificar se as expressões aparecem textualmente } \\
\text { nas decisões, sem prejuízo da identificação legal de } \\
\text { artigos próprios da CRFB } 88 \text { e do CPC } 2015 \text {. }\end{array}$ \\
\hline Artigo 93 & $\begin{array}{l}\text { Identificar a existência ou não de referência ao artigo } \\
\text { 93, IX da CRFB 88, no texto legal das decisões } \\
\text { fundamentadas ou não. }\end{array}$ \\
\hline Artigo 489 & $\begin{array}{l}\text { Identificar a existência ou não de referência ao artigo } \\
489 \text { do CPC 2015, como referência legal das } \\
\text { decisões fundamentadas ou não. }\end{array}$ \\
\hline
\end{tabular}

\footnotetext{
${ }^{13}$ Importante o registro que a pesquisa de cada expressão jurídica foi realizada com o uso de conector (e) disponível no próprio sitio de consulta jurisprudencial do Tribunal de Justiça do Rio de Janeiro disponível em http://www4.tjrj.jus.br/ejuris/ConsultarJurisprudencia.aspx. No caso das expressões referentes aos artigos jurídicos, após o início das atividades e um número não muito significativo de decisões, percebeu-se, por experimentação, que em muitos casos havia a utilização de abreviaturas (art.93, art. 489 e art. 932) pelos desembargadores, de modo que foram refeitas buscas já realizadas e a partir daquele momento, adotada a dupla pesquisa em cada uma das Câmaras Cíveis e de Consumo do Tribunal de Justiça do Rio de Janeiro.
} 


\begin{tabular}{|l|l|}
\hline Artigo 932 & $\begin{array}{l}\text { Identificar a existência de decisões monocráticas (ou } \\
\text { colegiadas referenciando as decisões monocráticas, } \\
\text { em especial interesse nos incisos, IV e V, referente } \\
\text { aos precedentes legalmente instituídos no CPC 2015. }\end{array}$ \\
\hline
\end{tabular}

Com as expressões jurídicas acima destacadas e seus objetivos iniciais, a coleta de dados foi sendo realizada e também consolidada ao final, levando em consideração os julgamentos ocorridos no ano de 2017. Mesmo ciente da vigência do CPC 2015 já em 2016, optou-se em meio às atividades de planejamento, por realizar um recorte temporal mais linear, ao contrário da ideia inicial de envolver ainda decisões de 2016. Tal posicionamento levou em consideração a própria transição legislativa e possibilidade de coleta de casos discutíveis em termos de aplicação da lei processual no tempo, publicações a posterior de decisões já proferidas no âmbito do CPC 1973, principalmente.

Partindo então das expressões jurídicas acima apontadas, a investigação encontrou resultados diversos entre as Câmaras Cíveis e de Consumo no Tribunal de Justiça do Estado do Rio de Janeiro. Tal diversidade não restou adstrita a um ou outro ponto isolado, sendo detectadas variações de volume de casos julgados, o que certamente tem explicações no campo da organização judiciária, quadro de composição de desembargadores e serventuários e até mesmo questões relacionadas à distribuição por prevenção e outros temas afins que não foram objeto da investigação retratada.

Assim, a análise qualitativa dos dados leva em consideração os aspectos relacionados à existência ou não das expressões jurídicas nas decisões, não sendo, necessariamente relevante para os propósitos do trabalho, comparar o número de decisões proferidas entre os órgãos julgadores, em sentido comparado. Aqui interessa entender as decisões que falam textualmente de fundamentação e precedentes, mas não fazem referência, por exemplo ao artigo 489 do CPC 2015, decisões que foram tomadas pelo relator com base no art. 932, IV ou V, mas não fazem referências textuais à expressões fundamentação ou precedente e outras possíveis variações.

Assim, com as ressalvas de praxe, seguem os dados obtidos na pesquisa e na sequência algumas observações a respeito dos resultados envolvendo as expressões jurídicas individualizadas: 
TABELA 2 - RESULTADOS GERAIS QUANTITATIVOS DA PESQUISA

\begin{tabular}{|c|c|c|c|c|}
\hline $\begin{array}{l}\text { Órgão x Expressões X } \\
\text { Número de decisões }\end{array}$ & $\begin{array}{c}\text { Fundamentação } \\
\text { e Precedente }\end{array}$ & Artigo e 93 & Artigo e 489 & $\begin{array}{c}\text { Artigo e } \\
932\end{array}$ \\
\hline 1ª Câmara Cível $^{\text {a }}$ & 10 & 09 & 05 & 39 \\
\hline $2^{\mathrm{a}}$ Câmara Cível & 11 & 13 & 32 & 188 \\
\hline $3^{\text {a }}$ Câmara Cível & 10 & 46 & 31 & 186 \\
\hline $4^{a}$ Câmara Cível & 141 & 27 & 137 & 533 \\
\hline $5^{\text {a Câmara Cível }}$ & 24 & 14 & 46 & 233 \\
\hline $6^{a}$ Câmara Cível & 20 & 21 & 10 & 588 \\
\hline $7^{\text {a }}$ Câmara Cível & 05 & 10 & 10 & 952 \\
\hline $8^{\text {a }}$ Câmara Cível & 18 & 02 & 30 & 325 \\
\hline $9^{a}$ Câmara Cível & 33 & 10 & 17 & 144 \\
\hline 10ª Câmara Cível & 22 & 14 & 197 & 436 \\
\hline 11ª Câmara Cível & 14 & 23 & 09 & 220 \\
\hline 12 Câmara Cível & 11 & 10 & 456 & 452 \\
\hline $13^{a}$ Câmara Cível & 13 & 23 & 09 & 777 \\
\hline 14 a Câmara Cível & 45 & 34 & 36 & 104 \\
\hline 15 a Câmara Cível & 05 & 09 & 06 & 241 \\
\hline 16 ${ }^{\mathrm{a}}$ Câmara Cível & 39 & 16 & 100 & 1381 \\
\hline 17 Câmara Cível & 05 & 09 & 07 & 453 \\
\hline $18^{\mathrm{a}}$ Câmara Cível & 08 & 06 & 08 & 158 \\
\hline 19ª Câmara Cível & 62 & 26 & 62 & 1256 \\
\hline 20ª Câmara Cível & 76 & 11 & 76 & 269 \\
\hline 21 ${ }^{\mathrm{a}}$ Câmara Cível & 27 & 34 & 14 & 293 \\
\hline 22ª Câmara Cível & 08 & 11 & 04 & 188 \\
\hline 23 $^{\text {a Câmara Cív/ Cons }}$ & 09 & 74 & 24 & 376 \\
\hline 24 a Câmara Cív/ Cons & 76 & 44 & 14 & 741 \\
\hline 25 ${ }^{\mathrm{a}}$ Câmara Cível/Cons & 60 & 49 & 424 & 753 \\
\hline $26^{\mathrm{a}}$ Câmara Cível/Cons & 24 & 17 & 12 & 280 \\
\hline $27^{\mathrm{a}}$ Câmara Cível/Cons ${ }^{14}$ & 21 & 98 & 58 & 905 \\
\hline
\end{tabular}

\subsection{Os resultados qualitativos envolvendo as expressões jurídicas Fundamentação e}

\section{Precedente.}

Como acima identificado, a análise por expressões jurídicas distintas, mas em tese versando aparentemente sobre o mesmo tema teve objetivos distintos, pois a proposta de investigação não versava apenas sobre aspectos quantitativos, muito menos pretendia, com a pesquisa proposta e realizada, esgotar o tema macro. Ao contrário os resultados apresentados sugerem interessantes indagações que poderão permitir que outras pesquisas possam aprofundar assuntos aqui tratados.

\footnotetext{
${ }^{14}$ Câmaras Cíveis com competência Cível e do Consumidor.
} 
Em especial atenção às expressões jurídicas Fundamentação e Precedente, os resultados demonstraram, ainda que com algumas distorções quanto ao número total de decisões se compararmos alguns órgãos julgadores, que tais expressões não necessariamente aparecem no quantitativo total das decisões obtidas com os demais critérios de pesquisa apontados do referido órgão julgador, isto é, as expressões Fundamentação e Precedente aparecem em um número muito pequeno das decisões. Toma-se como exemplo, os dados da $2^{\mathrm{a}}$ Câmara Cível, que tem apresenta 11 entre acórdãos e decisões monocráticas, coerente com a expressão constitucional do art. 93, IX, mas em visível desequilíbrio, se comparado com as demais expressões pesquisadas, além da clara existência de Câmaras em maior equilíbrio e outras com predomínio das referidas expressões se comparado aos demais artigos legais investigados.

É oportuno também salientar que a ausência textual das expressões Fundamentação $e$ Precedente não significa, por si só, ausência de fundamentação legal ou constitucional. Tratase apenas de um resultado que será objeto de análise no item das conclusões e poderá ainda, render outros estudos e investigações mais aprofundadas.

Via de regra, as referidas expressões estão mais próximas e são identificadas com o texto constitucional do artigo 93, IX do que com as demais expressões legais.

\subsection{Os resultados qualitativos envolvendo as expressões jurídicas Artigo 93, em referência ao artigo 93, IX da CRFB 88.}

A análise da mesma Tabela 2 acima permite enxergar também os resultados obtidos para as expressões jurídicas em referência ao artigo 93, IX da CRFB 88, o que é muito significativo, pois até bem pouco tempo, antes da vigência do CPC 2015, tal dispositivo constitucional, se comparado à parca normativa do CPC 1973, LICC e posteriormente LINDB, reinava como um mandamento a ser preenchido pela materialidade das tradicionais fontes do Direito, acrescidos dos movimentos mais recentes pautados na ponderação de interesses, maior valorização dos Princípios Constitucionais, efeitos normativos e a interpretação constitucional que principalmente o Supremo Tribunal Federal vem adotando em casos mais emblemáticos de controle de constitucionalidade e arguição de descumprimento de preceito fundamental. 
Mais uma vez, embora os números não sejam linearmente proporcionais, percebe-se uma maior utilização da referência ao artigo 93, IX da CRFB 88 do que as próprias expressões Fundamentação e Precedente, fruto aqui muito provavelmente relacionado ao lastro doutrinário e jurisprudência da ausência normativa hoje existem no artigo 489 do CPC 2015, ainda que exista uma clara identificação entre elas.

\subsection{Os resultados envolvendo as expressões jurídicas Artigo e 489 em referência ao artigo 489 do CPC 2015.}

Com referência inicial a mesma tabela 2, percebe-se um resultado mais aleatório em relação ao uso e referência ao artigo do CPC 2015 que foi concebido para ser o normatizador central da fundamentação ou não das decisões judiciais. O referido artigo contempla os elementos formais e materiais da sentença e a partir de seu parágrafo primeiro, as disposições a respeito das situações jurídicas que caracterizam uma decisão judicial, seja ela qual for, como não fundamentada e portanto, nula de pleno direito.

Assim, a existência ou não de referência textual ao artigo 489, em especial ao seu parágrafo primeiro, e em especial aos incisos, V e VI, em decisões judiciais que são proferidas com base em decisões pretéritas intituladas de precedentes é, no mínimo, um sinal de atenção e oportuna investigação. Pode ser apenas um retrato do profissional que esteja, ao final, redigindo as decisões ou acórdãos, pode significar, no caso de ausência, de uma característica do referido órgão julgador em referenciar os precedentes em si, sem necessariamente aduzir ao dispositivo legal, sendo tal papel mais direcionado aos advogados em suas peças recursais, mais propícias ao ataque pela tipicidade ou não de atos e fatos processuais.

O caso da $4^{\mathrm{a}}$ Câmara Cível tem uma característica, qual seja de um alinhamento entre o uso das expressões Fundamentação e Precedente com as expressões artigo 489, demonstrando, ao menos nesse quesito, um reconhecimento expresso das decisões em associar as termos legais doutrinários aos respectivos dispositivos legais, o que é mais fácil de compreender do que a simples ausência, ou número muito reduzido utilização de um ou outro, em especial do artigo de lei, considerando o aspecto mais formal das decisões monocráticas e colegiadas. 
Considerando que as decisões pesquisadas forma proferidas no decorrer do ano de 2017, ainda que os processos tenham tido início e fases anteriores ao novo diploma processual, era de se esperar uma maior ocorrência ou associação ao artigo 489 do CPC 2015, principalmente se comparados aos resultados do próximo item, mais específico às decisões monocráticas, bem como o julgamento dos processos nos tribunais com base no nos incisos, III, IV e V do artigo 932, que contempla os poderes de atuação do relator.

\subsection{Os resultados qualitativos envolvendo as expressões jurídicas Artigo 489, em referência ao artigo 489 do CPC 2015.}

A respeito da busca com Artigo 489, em referência ao artigo 489 do CPC 2015, com exceção de algumas poucas Câmaras Cíveis e Consumo em que aparecem números maiores (mas mesmo assim inferiores às aparições do Art. 932), o tema continua timidamente presente nas decisões, também revelando uma não preocupação formal de referenciar o dispositivo legal central, havendo existência do previsão legal no próprio artigo 932, incisos IV e V, que indicam, inclusive, os casos de precedentes para fins de aplicação pelo julgador.

No entanto, casos como da $12^{\mathrm{a}}$ Câmara Cível revelam, ainda que por razões pontuais, uma sincronia de tipificação legal do artigo 489 do CPC nas decisões judiciais, em companhia quase que constante do artigo 932 do CPC, demonstrando que em grande proporção, os relatores decidiram casos envolvendo falta ou discordância (ou alegação de ) de fundamentação, uma vez que presentes o referido dispositivo legal em suas julgados monocráticos e colegiados.

\subsection{Os resultados qualitativos envolvendo as expressões jurídicas Artigo e 932 em referência ao artigo 932 do CPC 2015.}

A visão inicial dos resultados quantitativos obtidos já demonstra uma disparidade entre a expressão legal referente aos poderes do relator, em especial ao julgamento por precedentes, com base nos incisos IV e V do artigo 932 do CPC. A disparidade quantitativa inicialmente tem um significado muito forte, qual seja, a efetiva realização de julgamentos monocráticos com base nos incisos IV e V, referente ao uso de precedentes, mas também com enorme incidência 
do inciso III, referente a extinção dos casos de recursos inamissíveis, prejudicados ou mesmo por falta de fundamentação legal.

É dado relevante para a pesquisa a constatação de que efetivamente as Câmaras Cíveis e Consumo atuem com base nos precedentes legalmente instituídos no âmbito do CPC, ainda que no campo doutrinário o tema possa restar ainda bem polêmico, em especial com a diversidade sobre o que venha a ser um precedente judicial. ${ }^{15} \mathrm{O}$ fato é que a investigação demonstra também, já em análise qualitativa, comparando em especial a expressão Artigo $e$ 932, em relação às demais expressões, um total descolamento da utilização das expressões Fundamentação, Precedente, Artigo 93 e Artigo 489, o que pode ter algumas razões propostas a seguir.

Com relação à utilização das expressões Fundamentação e Precedente encontramos o maior descolamento, fazendo-se valer o relator desembargador da praticidade e objetividade do artigo 932, IV e V do CPC 2015, sem entender necessário a utilização de termos, aqui no caso, mais extensos ao campo doutrinário.

No tocante à expressão Artigo 93, em referência ao artigo 93, IX da CRFB 88, ainda que exista o maior de todos os distanciamentos em referência à cronologia legal ( 1988), a tradição e ausência de dispositivo infraconstitucional específico( o artigo 489 surge apenas em 2015), explicam, em tese, o apego e sentimento de referência ao texto constitucional. Por assim dizer, na dúvida, o artigo 93, IX da CRFB 88 abraça a todas as causas, tem um caráter macro, sem prejuízo da recente especificidade do artigo 489 do CPC 2015.

\section{CONCluSÕES, POSSÍveIS TEMAS DE INTERESSE PARA NOVAS INVESTIGAÇÕES E CONSIDERAÇÕES FINAIS}

Pela ordem, é importante que se confirme que a investigação efetivamente identificou a utilização de precedentes judiciais, nos termos previstos no artigo 932, IV e VI, bem como

\footnotetext{
${ }^{15}$ STREK, Lênio, ABBOUD, Georges. O que é isto - o precedente judicial e as súmulas vinculantes? $2^{\mathrm{a}}$. Ed. Porto Alegre: Livraria do Advogado, 2014, p. 45-46.
} 
também reproduzidos no artigo 332 do CPC 2015, sem prejuízo das disposições pertinentes nas disposições contidas no Livro III, Título I, artigos 926 a 928 ( Disposições Gerais); artigos 929 a 946 (Ordem dos Processos nos Tribunais) e outros momentos do diploma processual que o legislador menciona a existência de precedentes, ou mesmo a sua formação e efeito vinculativo, a partir de determinada decisão no tribunal local ou mesmo tribunal superior. ${ }^{16}$

Assim, a primeira conclusão que se chega é da efetiva utilização de precedentes pelos órgãos colegiados do Tribunal de Justiça aqui investigados ( Câmaras Cíveis e de Consumidor), quais sejam, as súmulas do Supremo Tribunal Federal, Superior Tribunal de Justiça e do próprio Tribunal de Justiça do Estado do Rio de Janeiro, acórdão proferido pelo Supremo Tribunal Federal ou pelo Superior Tribunal de Justiça em julgamento de recursos repetitivos, entendimentos firmados em incidentes de resolução de demandas repetitivas e assunção de competência.

Ainda derivada da conclusão primeira, aponta-se que tais julgamentos têm ocorrido com grande intensidade em decisões monocráticas, fundadas no artigo 932, IV e V, e ainda com incidência do inciso III, não necessariamente relacionado ao tema de precedentes, mas com possibilidade de haver hipóteses firmadas neste sentido.

Interessante são as conclusões derivadas de análise teórica e mais qualitativa, levando em consideração a combinação dos dados obtidos na investigação, partindo, de algumas colações apresentadas individualmente sobre as expressões jurídicas investigadas, como por exemplo, a respeito do uso ou não de Fundamentação e Precedente de modo textual nas decisões.

Com exceção da $4^{\mathrm{a}}$ Câmara Cível, o baixo índice de utilização das expressões revela uma nítida opção da formatação decisória com tipificação mais restrita a lei, em especial, ao artigo 932 e, quando muito, ao artigo 489, ambos do CPC 2015. Denota também que o uso do discurso mais doutrinário não predomina em casos de julgamentos de precedentes ou alegações, por exemplo, de falta de fundamentação legal, o que por sua vez, demonstra que a arquitetura

\footnotetext{
${ }^{16}$ Aqui, especial referência aos casos dos incidentes de Assunção de Competência e Resolução de Demandas Repetitivas que geram decisões com a possibilidade de vinculação, como precedente, aos demais casos futuros.
} 
dos precedentes, desde as antigas referências do artigo 557 e outros do CPC 1973 efetivamente ocorreu no sistema processual pátrio.

Já no tocante à não presença do artigo 93, IX da CRFB 88 nos julgados ,(salvo algumas exceções pontuais), demonstra o desapego de sua citação em caso de julgamento de precedentes, mas ao mesmo tempo, em outros temas, a guarda da CRFB 88 continua sendo utilizada como reclame ou validação de fundamentação nas decisões. Não por outra razão, os números são similares às expressões Fundamentação e Precedente juntas, o que demonstra que ainda se discute precedente com a CRFB 88 mais do que com o próprio CPC 2015, em especial os artigos 489 e 932, quando do julgamento de relatores e colegiados.

A conclusão mais retilínea envolve a não presença do artigo 489 do CPC 2015 em decisões os precedentes do artigo 932, IV e V, também do CPC 2015. Ora, apesar do predomínio quantitativo de decisões (a maioria decisões monocráticas) julgando com base em precedentes, é ínfima a menção ao artigo normatização da fundamentação no diploma processual.

Da conclusão acima, é possível afirmar ainda que os julgamentos pautados em precedentes com base na normativa do artigo 932 não tem ferido a normativa da fundamentação específica, prevista nos incisos V e VI do $\S 1^{\circ}$ do artigo 489 do CPC ou não tem despertado a atenção dos advogados, no caso de possíveis alegações de nulidade decisória.

Por óbvio que o tema é sugestivo para outras investigações mais qualitativas e profundas, adentrando à pretensão material e demais itens de regularidade processual, o que não foi objeto da investigação proposta e que certamente poderão revelar pormenores da correta utilização ou não de precedentes ao caso concreto.

A majoritária incidência do artigo 932 do CPC 2015, em especial atenção aos incisos III, IV e V, revela em análise primária, do fortalecimento dos poderes do relator, transformando os órgãos colegiados em atuação complementária a de seus desembargadores que iniciam a atividade de relatar os autos de cada processo individual.

A nova redação dada ao artigo 932 do CPC 2015, a exemplo também do artigo 332 do mesmo diploma, proporcionou a concentração de poderes ao julgador monocrático, permitindo aos desembargadores e juízes de primeiro grau, proferir decisões de mérito com base em 
precedentes. Daí a multiplicidade de sentenças liminares e também recursos decididos monocraticamente, o que no presente caso reflete os números apresentados na pesquisa.

Ao finalizar o presente artigo, resta a certeza de que a pesquisa realizada trouxe além de conclusões, possibilidades e sugestões de novas investigações futuras, seja em face das mesmas decisões e órgãos, seja em face da atuação do Superior Tribunal de Justiça e Supremo Tribunal Federal na temática dos precedentes, com especial atenção à atividade criadora de paradigmas de recursos repetitivos, de repercussão geral e controle de constitucionalidade, os dois últimos na Corte Suprema, por óbvio.

\section{REFERÊNCIAS BIBLIOGRÁFICAS}

ALMEIDA, Marcelo Pereira de. Precedentes Judiciais. Análise Crítica dos Métodos Empregados no Brasil para a solução de Demandas de Massa. Curitiba: Juruá Editora, 2014.

AVILA, Humberto, Teoria dos Princípios da definição à aplicação dos Princípios jurídicos. São Paulo: Ed. Malheiros, 2014.

BRASIL. CÓDIGO DE PROCESSO CIVIL. Disponível em http://www.planalto.gov.br/ccivil_03/Leis/L5869.htm

BRASIL. CONSTITUIÇÃO DA REPÚBLICA FEDERATIVA DO BRASIL. Disponível em http://www.planalto.gov.br/ccivil_03/constituicao/constituicaocompilado.htm

BRASIL. CÓDIGO DE PROCESSO CIVIL. Disponível em http://www.planalto.gov.br/ccivil_03/_ato2015-2018/2015/lei/113105.htm

BRASIL. PODER JUDICIÁRIO DO ESTADO DO RIO DE JANEIRO. Consulta Jurisprudencial Disponível em http://www4.tjrj.jus.br/ejuris/ConsultarJurisprudencia.aspx

COSTA, José Augusto Galdino da. Princípios Gerais no Processo Civil. Princípios Fundamentais e Princípios Informativos. Rio de Janeiro: Ed. Forense, 2007.

CATHARINA, Alexandre de Castro. Movimentos Sociais e a construção dos procedentes judiciais. Curitiba: Ed. Juruá, 2015.

MARINONI, Luiz Guilherme. Teoria Geral do Processo. Curso de Processo Civil. Vol 1. São Paulo: Editora Revista dos Tribunais, 2010.

MARTÍN, Nuria Belloso. O neoconstitucionalismo e o "novo" constitucionalismo latinoamericano: Duas correntes possíveis de entendimento? In, Revista Culturas Jurídicas. 
Teoria Crítica Teoria Crítica, Pluralismo Jurídico e as Américas, Pluralismo Jurídico e as Américas. Vol. 4, Núm. 9, set./dez., 2017, pp. 24-54.

MOLLER, M., Teoria Geral do Neconstitucionalismo, Bases Teóricas do Constitucionalismo Contemporâneo. Porto Alegre: Ed. Livraria do Advogado,2011, p.50.

PINTO, Adriano Moura da Fonseca; LUCAS, Isabella Pena; ALMEIDA, Marcelo Pereira de; NETO, Ubirajara da Fonseca. Na Marcha da Reforma Processual. Comentários às Leis 11.382/06; 11.417/06; 11.418/06; 11.419/06; 11.441/07; 11.448/07 e outras anotações. Rio de Janeiro: Freitas Bastos Editora, 2007.

PEREIRA, Fabrício de Souza Lopes. Resolução de Demandas Repetitivas, Ações Coletivas e Precedentes Judiciais. Curitiba: Juruá, 2017.

RODRIGUES, Saulo Tarso. Teoria da Decisão Judicial e Teoria da Justiça. Jusfilosofia e Novos Paradigmas Constitucionais. [et al]. Curitiba: Juruá, 2015.

SILVA, Acioli Viana. ...[et].4. Novo Código de Processo Civil Comparado e Anotado. 2 ed. Rio de Janeiro: Mundo Jurídico, 2017.

STREK, Lênio, ABBOUD, Georges. O que é isto - o precedente judicial e as súmulas vinculantes? 2a ${ }^{\text {a }}$ Ed. Porto Alegre: Livraria do Advogado, 2014.

WENECK VIANNA, L. ... [et al]. A judiciaização da política e das relações sociais no Brasil. Rio de Janeiro: Ed. Revan, 1999.

Data de Submissão: 01/08/2020

Data de Aceite: 12/08/2020 